\title{
APLICAÇÃO DE REDES NEURAIS ARTIFICIAIS NA PREVISÃO DA PRODUÇÃO DE ÁLCOOL
}

\author{
Application of artificial neural networks in the forecast of \\ alcohol production
}

\author{
Anderson Castro Soares de Oliveira ${ }^{1}$, Ademária Aparecida de Souza ${ }^{1}$, \\ Wilian Soares Lacerda ${ }^{2}$, Luciene Resende Gonçalves ${ }^{1}$
}

\begin{abstract}
RESUMO
Este trabalho descreve a aplicação de Redes Neurais Artificiais na tarefa de previsão da produção de álcool no Brasil no ano de 2006, a partir de dados de produção anteriores. É também apresentada uma comparação entre os resultados obtidos por meio da Rede Neural com os obtidos utilizando técnicas de séries temporais, sendo que a Rede Neural obteve melhores resultados.
\end{abstract}

Termos para indexação: Álcool, Redes Neurais, Séries Temporais.

\begin{abstract}
This work describes the application of Artificial Neural Networks in the forecasting of alcohol production in Brazil in the year of 2006 using past data. Results obtained through Neural Networks were compared to those obtained using time series techniques, and Neural Networks have shown better results.
\end{abstract}

Index terms: Alcohol, Neural Networks, Time Series.

(Recebido em 13 de janeiro de 2009 e aprovado em 15 de julho de 2009)

\section{INTRODUÇÃO}

A energia utilizada pela humanidade tem sido extraída, principalmente, de combustíveis fósseis como o gás natural, o petróleo e o carvão. Essa utilização intensa dos materiais energéticos fósseis aliados à agricultura extensiva e outros fatores que alteram a biosfera, tem resultado num acréscimo mensurável da concentração de gás carbônico na atmosfera. Tornando, cada vez mais crescente, a necessidade da utilização de fontes alternativas de energia.

Dentre as diversas formas renováveis de energia pode-se citar o álcool o qual tem tido seu reconhecimento na comunidade internacional como uma das fontes mais viáveis atualmente, destacando-se como um dos melhores candidatos a serem apoiados com políticas de financiamento, segundo estabelecido no Protocolo de Kyoto (Leite, 1997).

A previsão de produção de álcool favorece uma tomada de decisões no sentido de planejar o volume de estoque para o consumo ao longo dos períodos subsequentes, principalmente agora, momento de transição da era fóssil para a era alternativa (Gonçalves, 2007).
Recentemente, Gonçalves (2007) fez um estudo das principais fontes de energia que compõem o setor energético brasileiro constituído por fontes renováveis e não renováveis. Para tal, foram utilizadas técnicas de modelagem de séries temporais como os modelos de Box \& Jenkins (1976), sendo considerados para previsão modelos com e sem intervenção. Para a produção de álcool, o modelo com intervenção obteve melhores previsões.

Box \& Jenkins (1976) propuseram modelos matemáticos que visam a captar o comportamento da correlação serial ou autocorrelação entre os valores da série temporal. Estes ficaram conhecidos como modelos ARIMA (Auto Regressive Integrated Moving Averages). Essa metodologia leva em conta que se os erros são sucessivamente dependentes, as observações também o serão. Desta forma, constrói-se modelos que descrevem com precisão, e de forma parcimoniosa, o processo gerador da série temporal, proporcionando assim previsões acuradas de valores futuros.

Os modelos ARIMA exploram a autocorrelação entre os valores da série em instantes sucessivos. Entretanto, em algumas séries temporais observa-se a existência de uma componente periódica sazonal que se

1Universidade Federal de Lavras/UFLA - Departamento de Ciências Exatas/DEX - Lavras, MG

${ }^{2}$ Universidade Federal de Lavras/UFLA - Departamento de Ciência da Computação/DCC - Cx. P. 3037 - 37200-000 - Lavras, MG - lacerda@ufla.br 
repete a cada $s(s>1)$ observações, implicando em correlação alta em períodos múltiplos de $s$. Dessa forma, é necessário considerar uma componente sazonal estocástica dentro do modelo que se ajuste à serie original. A classe de modelos que contempla séries que apresentam autocorrelação sazonal são conhecidas como SARIMA.

Por outro lado, Redes Neurais Artificiais (RNAs) vêm sendo empregadas com sucesso na previsão de séries temporais, por sua capacidade de aproximar funções nãolineares (Fernandes et al., 1996; Calôba et al., 2002; Torres et al., 2005). Assim, o objetivo principal deste trabalho é propor um modelo de previsão da produção de álcool utilizando Redes Neurais Artificiais e comparar com os resultados obtidos por Gonçalves (2007).

Uma Rede Neural Artificial Multicamadas (Haykin, 1999) é tipicamente composta de camadas alinhadas de neurônios, conforme é mostrado na Figura 1. Nesse tipo de rede, as entradas são apresentadas na primeira camada, que é chamada camada de entrada. Essa camada distribui as informações para a(s) camada(s) escondida(s) da rede. A última camada é a camada de saída, onde a solução do problema é obtida. A camada de entrada e a camada de saída podem ser separadas por uma ou mais camadas intermediárias (ou camadas escondidas). Além disso, os neurônios de uma camada estão conectados apenas aos neurônios da camada imediatamente posterior, não havendo realimentação (comunicação unidirecional) nem conexões entre neurônios da mesma camada.

Basicamente, o treinamento de uma RNA consiste em um problema de minimização não linear sem restrições, em que os pesos sinápticos da rede são iterativamente modificados para minimizar o erro quadrático médio entre a resposta desejada a partir dos dados de entrada e a saída obtida no neurônio de saída. Do ponto de vista estatístico, treinamento significa estimar os parâmetros do modelo considerando-se um conjunto de dados.

Em qualquer problema a ser resolvido por meio do uso de RNAs, é necessário o uso de pares de entradasaída já conhecidos. Muitas vezes, a quantidade de pares disponíveis não é muito grande, mesmo assim deve-se separar esses dados em pelo menos dois conjuntos bem definidos: o conjunto de treinamento e o conjunto de teste.

\section{MATERIAL E MÉTODOS}

Os dados propostos para o estudo referem-se à série histórica da produção mensal de álcool de cana-de- açúcar nível 80 - índice (média 2002=100), coletada no período de janeiro de 1991 a setembro de 2006, num total de 186 observações. Esses dados foram obtidos junto ao banco de dados do Instituto de Pesquisas Econômicas Aplicadas (Instituto de Pesquisa Econômica AplicadaIPEA, 2007).

Para implementar a RNA utilizou-se a seguinte estrutura após exaustivas tentativas: 12 neurônios na camada de entrada, uma camada escondida com 48 neurônios, e um neurônio na camada de saída. Todos neurônios com função de ativação sigmoidal. O algoritmo utilizado para o treinamento foi o algoritmo de retropropagação (backpropagation) com momentum, com uma taxa de aprendizagem de 0.01 , e taxa de momentum de 0.01. Definiu-se o conjunto de treinamento composto pelas observações da produção de álcool durante o período de janeiro de 1991 a dezembro de 1999. Os dados do período de janeiro de 2000 a dezembro de 2005 foram destinados ao conjunto de teste. As observações do período de janeiro de 2006 a setembro do mesmo ano foram reservadas para serem comparadas com as previsões (conjunto de validação).

Para determinar a qualidade dos resultados obtidos pela RNA comparados aos obtidos por Gonçalves (2007), foram levados em consideração o grau de precisão das previsões consideradas, por dois critérios distintos:

1 - Erro percentual médio absoluto (MAPE), dado pela seguinte expressão:

$$
M A P E=\frac{1}{h} \sum_{i=1}^{h}\left|\frac{y_{i}-y_{p i}}{y_{i}}\right|
$$

2 - Erro quadrático médio de previsão (EQMP), expresso por:

$$
E Q M P=\frac{1}{h} \sum_{i=1}^{h}\left(y_{i}-y_{p i}\right)^{2}
$$

em que:

- $y_{i}$ é o valor real do período i;

- $y_{p i}$ é a previsão para o período i;

- h é o número de previsões. 


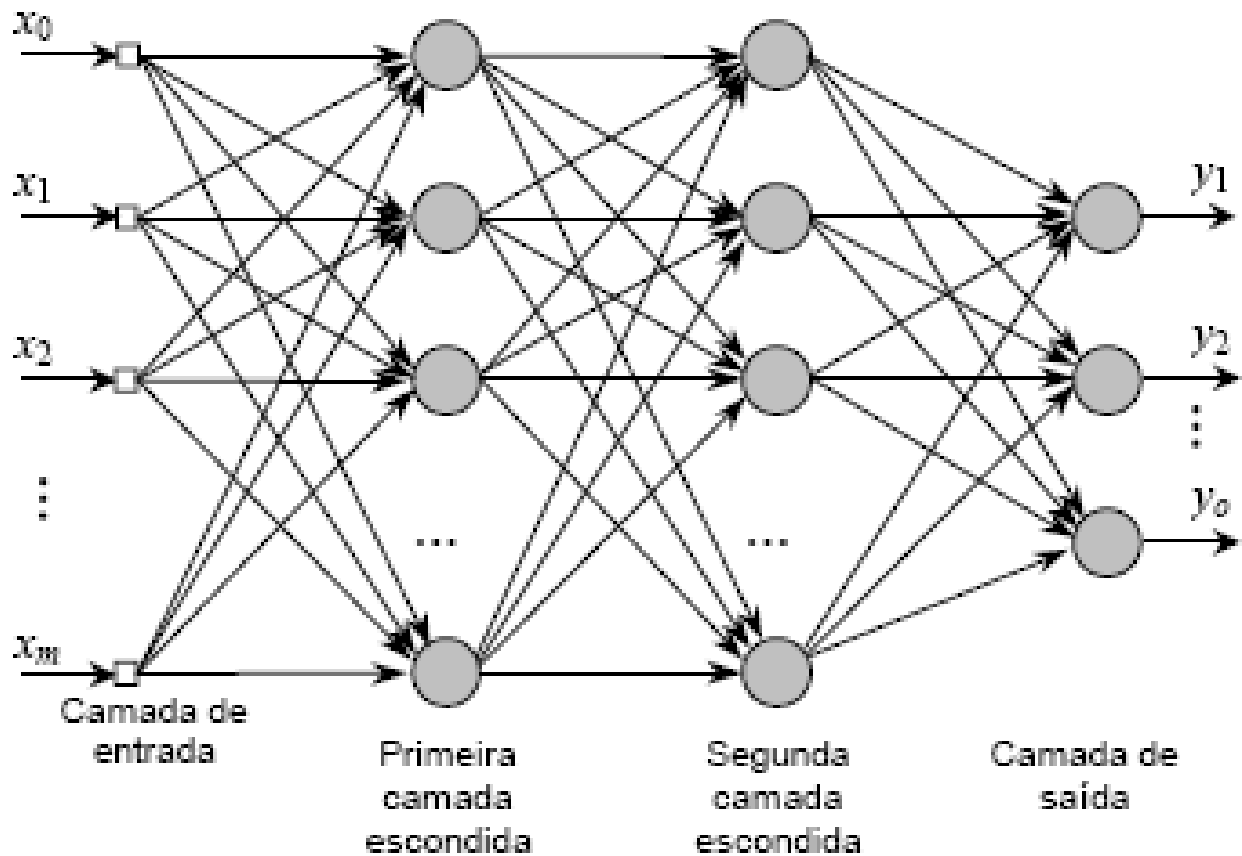

Figura 1 - Rede Neural Artificial Multicamadas.

\section{RESULTADOS E DISCUSSÃO}

Na Figura 2, é apresentado o gráfico original da série de produção de álcool (a) e sua função de autocorrelação (b). A estrutura da função de autocorrelação sugere que a série apresenta componente sazonal determinístico de período 12. Para confirmar a existência do efeito sazonal, nesse período, aplicou-se o teste de Fisher, em que obteve-se $\mathrm{g}=0,90$ e $\mathrm{z}_{0,05}=0,08$. Como $\mathrm{g}>\mathrm{z}$, a série apresenta sazonalidade de 12 meses, ao nível de 5\% de significância. Em outras palavras, a série apresenta uma dependência de 12 meses.

Dessa forma, no modelo da RNA foram utilizados dados de entrada atrasados de 12 meses, ou seja, para cada valor de saída da rede foram apresentados doze valores de entrada antigos. Na Figura 3, são apresentados os resultados obtidos pela RNA no conjunto de treinamento, teste e validação. $\mathrm{O}$ conjunto de treinamento foi utilizado para treinar a rede, o conjunto de teste para testar a generalização da rede durante o treinamento, e o conjunto de validação após o treinamento para verificar o seu desempenho final. Pode-se ver que as curvas geradas pela RNA têm, aproximadamente, a mesma forma que as curvas reais, demonstrando que a RNA modela de forma satisfatória o processo gerador dos dados.
Na Figura 4, é apresentado o comportamento do erro médio quadrático (EMQ) de treinamento e de teste durante o treinamento da RNA. Pode-se observar que, a partir da época 10.000 , o erro no conjunto de teste apresenta um comportamento aproximadamente constante, enquanto que o erro no conjunto de treinamento decresce. A partir desse momento, a capacidade de generalização da RNA não melhora significativamente, apesar de melhorar os acertos dos dados de treinamento.

Na Tabela 1, são apresentadas as previsões para os meses de janeiro a setembro de 2006 obtidos por Gonçalves (2007), por meio do modelo SARIMA $(1,0,0)(0,1,1)_{12}$ com intervenção e pela RNA $(12,48,1)$. Podese observar que a RNA apresentou previsões mais próximas dos valores reais, com exceção dos meses de janeiro e fevereiro.

Na Tabela 2, á apresentado o MAPE e o EQMP para as previsões obtidas por Gonçalves (2007), por meio do modelo SARIMA $(1,0,0)(0,1,1)_{12}$ com intervenção e pela RNA (12,48,1), para a produção álcool no período de janeiro de 2006 a setembro de 2006. Pode-se observar que as previsões obtidas por meio da RNA produziram não só o menor MAPE, como também o menor EQMP, conduzindo dessa maneira, a resultados mais precisos. 


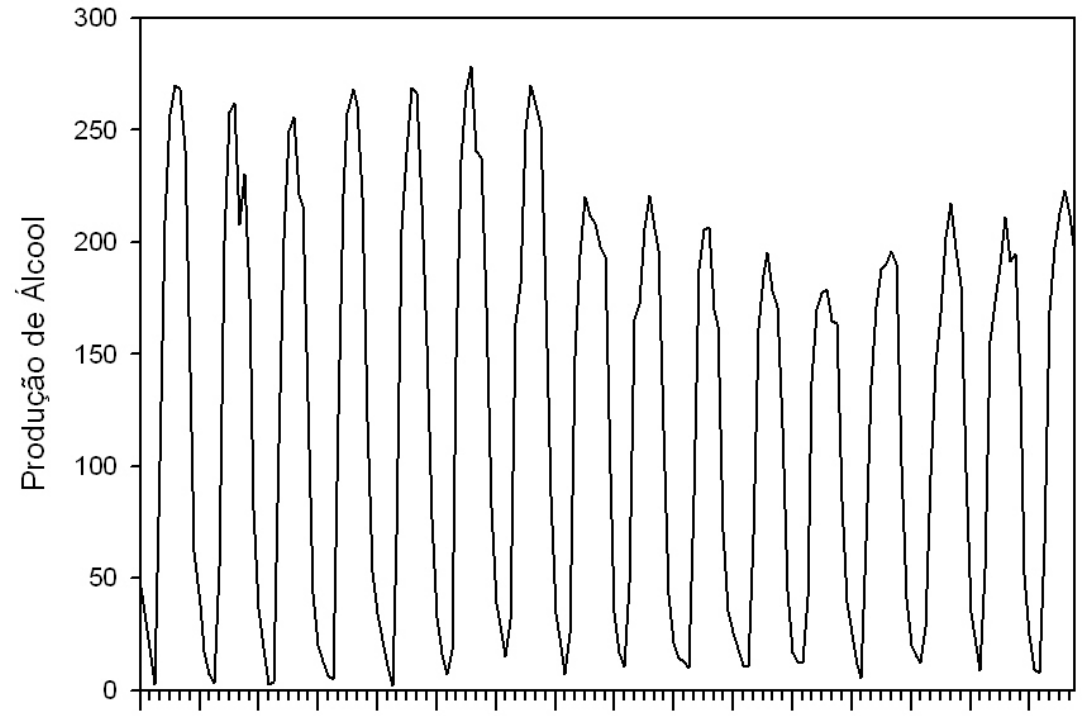

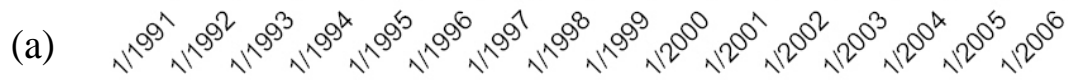

Mês

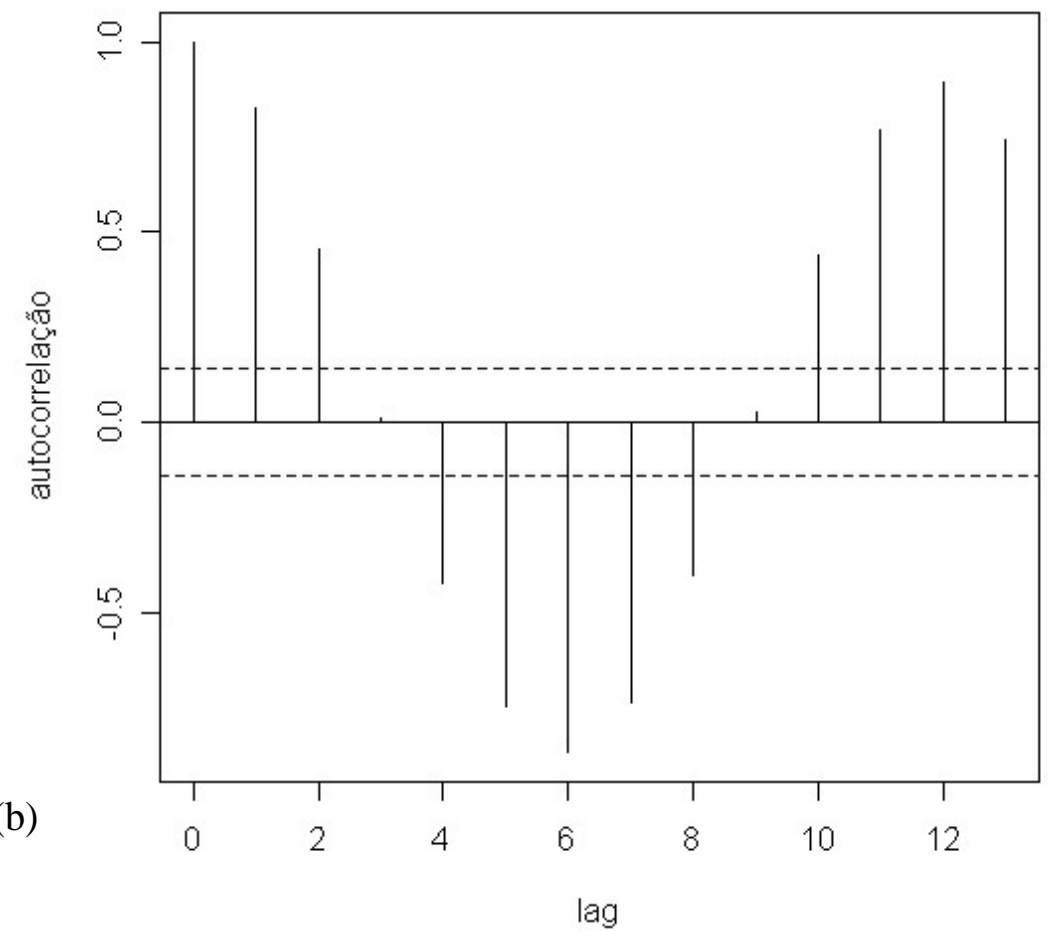

Figura 2 - Representação gráfica da série original (a) e da função de autocorrelação (b) de produção mensal de álcool nível 80 - índice (média 2002=100) no período de janeiro de 1991 a setembro de 2006. 


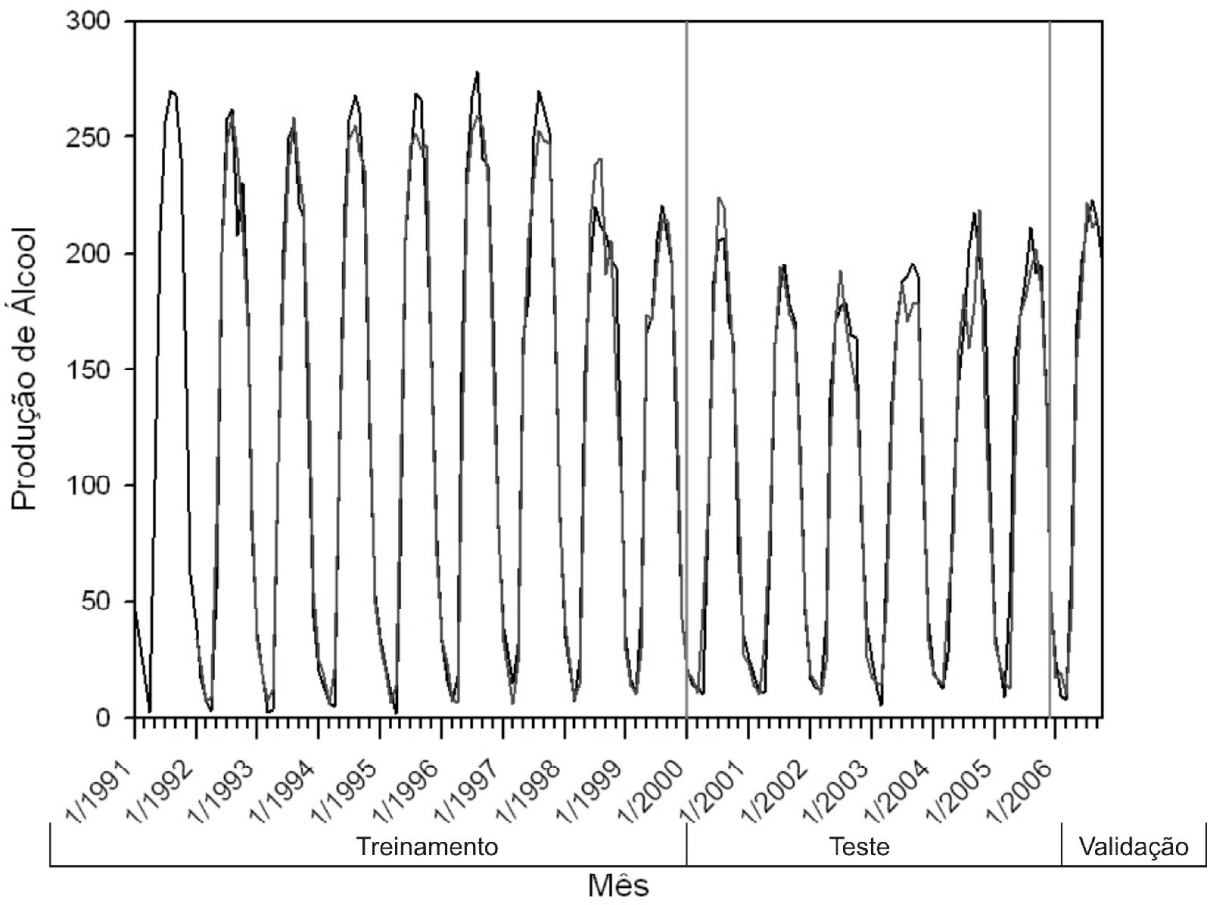

Figura 3 - Representação gráfica da série original (preto) e da prevista pela rede neural (cinza) de produção mensal de álcool nível 80 - índice (média 2002=100) no período de janeiro de 1991 a setembro de 2006. (Conjunto de treinamento: jan/ 1991 a dez/1999, conjunto de teste: jan/2000 a dez/2005, e conjunto de validação: jan/2006 a set/2006).

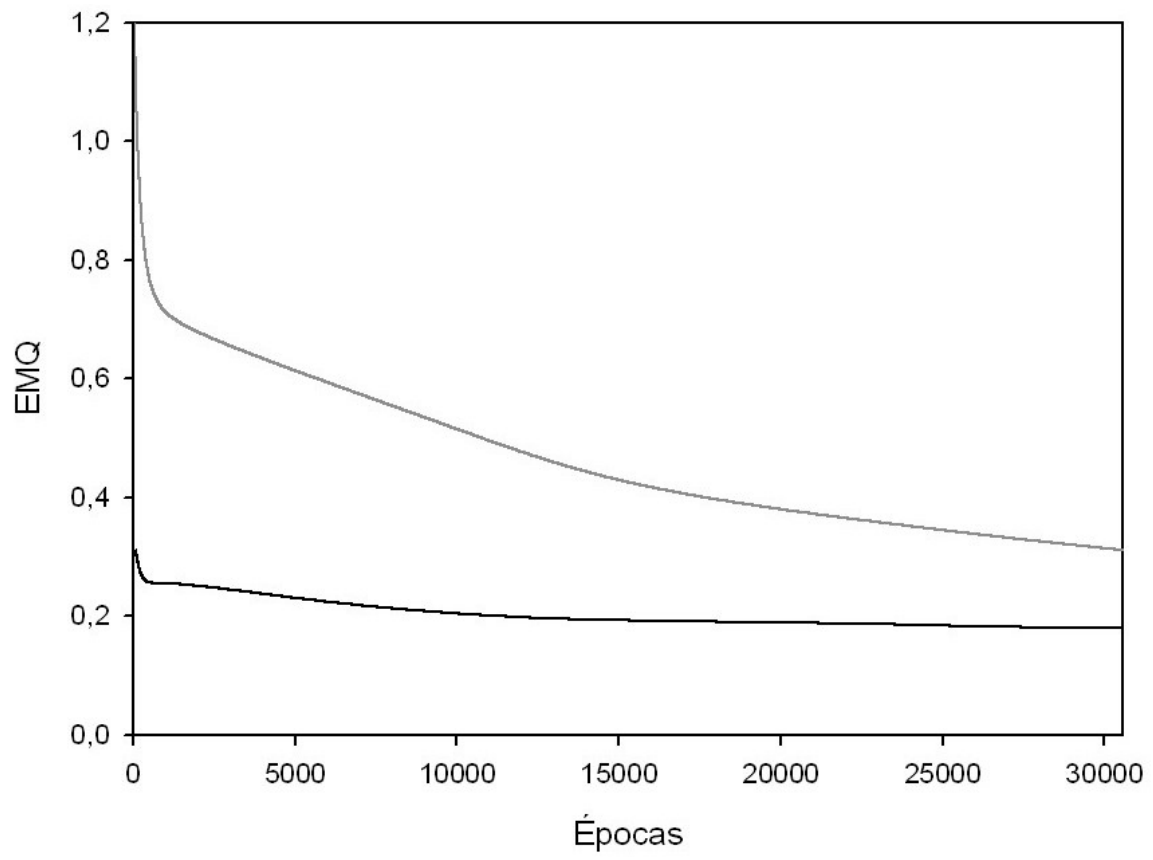

Figura 4 - Evolução dos erros de treinamento (cinza) e de teste (preto) durante o treinamento da RNA com 48 neurônios na camada intermediária. 
Tabela 1 - Valores reais de produção de álcool para o período de janeiro de 2006 a setembro de 2006 e valores previstos para o mesmo período por Gonçalves (2007) por meio do modelo SARIMA $(1,0,0)(0,1,1)_{12}$ com intervenção e pela RNA $(12,48,1)$.

\begin{tabular}{cccc}
\hline Mês & $\begin{array}{c}\text { Valor } \\
\text { Real }\end{array}$ & $\begin{array}{c}\text { SARIMA-CI } \\
(1,0,0)(0,1,1)_{12}\end{array}$ & $\begin{array}{c}\text { Rede Neural } \\
(12,48,1) \alpha=0.01\end{array}$ \\
\hline jan/06 & 24,78 & 23,35 & 17,61 \\
fev/06 & 9,43 & 16,68 & 19,43 \\
mar/06 & 7,48 & 12,12 & 10,04 \\
abr/06 & 65,66 & 45,16 & 46,83 \\
mai/06 & 169,60 & 131,54 & 155,36 \\
jun/06 & 197,85 & 171,94 & 187,28 \\
jul/06 & 213,14 & 191,51 & 221,68 \\
ago/06 & 223,15 & 208,18 & 211,29 \\
set/06 & 212,04 & 200,49 & 215,10 \\
\hline
\end{tabular}

Tabela 2 - Comparação da precisão das previsões obtidos por Gonçalves (2007), por meio do modelo SARIMA $(1,0,0)$ $(0,1,1)_{12}$ com intervenção e pela RNA $(12,48,1)$, para a produção álcool no período de janeiro de 2006 a setembro de 2006.

\begin{tabular}{lcr}
\hline Modelos & EQMP & MAPE \\
\hline $\begin{array}{l}\text { SARIMA }(1,0,0)(0,1,1)_{12} \\
\text { com intervenção }\end{array}$ & 382,4132 & $25,97 \%$ \\
Rede Neural $(12,48,1) \alpha=0.01$ & 116,6517 & $24,70 \%$ \\
\hline
\end{tabular}

\section{CONCLUSÕES}

A RNA implementada obteve uma previsão melhor para a produção de álcool do que aquela obtida por técnica de tratamento da série no domínio do tempo (séries temporais). Assim, foi possível verificar a eficiência da RNA ao tratamento de padrões não lineares e a sua aplicação na tarefa de previsão. Para a obtenção de melhores resultados, modificações na topologia e treinamento da RNA podem ser aplicadas tais como: variação da quantidade de neurônios, aumento do tempo de treinamento, teste com outros parâmetros de treinamento.

\section{AGRADECIMENTOS}

Os autores agradecem o apoio financeiro da FAPEMIG para a publicação deste artigo.

\section{REFERÊNCIAS BIBLIOGRÁFICAS}

BOX, G.E.P.; JENKINS, G.M. Time series analysis: forecasting and control. San Francisco: Holden-Day, 1970. 842p.

CALÔBA, G.M.; CALÔBA, L.P.; SALIBY, E. Cooperação entre redes neurais artificiais e técnicas clássicas para previsão de demanda de uma série de vendas de cerveja na Austrália. Pesquisa Operacional, v.22, n.3, p.345-358, 2002.

FERNANDES, L.G.L.; NAVAUX, P.O.A.; PORTUGAL, M.S. Previsão de séries de tempo: redes neurais e modelos estruturais. Pesquisa e Planejamento Econômico, v.26, n.2, p.253-276, 1996.

\section{GONÇALVES, L.R. Modelagem de séries} representativas do setor energético brasileiro. 2007. 106p. Dissertação (Mestrado em Estatística e Experimentação Agropecuária)-Universidade Federal de Lavras, Lavras, 2007.

HAYKIN, S. Neural networks, a comprehensive foundation. New Jersey: Englewood Cliffs, 1999. 842p.

INSTITUTO DE PESQUISA ECONÔMICA APLICADA. Disponível em: <ivww.ipeadata.gov.bri jun. 2007.

LEITE, A.D. A energia do Brasil. Rio de Janeiro: Nova Fronteira, 1997. 598p.

TORRES, R.; MACHADO, M.A.S.; SOUZA, R.C. Previsão de séries temporais de falhas em manutenção industrial usando redes neurais. Engevista, v.7, p.23, 2005. 